on Tremor Mercurialis and Paralysis Agitans." $†$ That the affection should be arranged under the class Neuroses, is proved by the cases just related. In the first case, which terminated fatally, the whole of the central nervous system was examined with the preatest care, but no lesion could be discovered. The disease was probably occasioned by mental emotion, but the presence of contracture of the limbs, with shooting pains, and pain along the spine, was calcu. lated to mislead the judgment, especially as the child suffered under pulmonary consumption. Indeed, nothing prevented the diagnosis of "tubercle of the spinal marrow" from being given, except the fact that this lesion of the nervous system is extremely rare, even in children. The case is an instructive one, and shows how very circumspect the medical man should be in the diagnosis of organic lesions of the nervous centres. In case 2 , the nervous tremor was evidently occasioned by the derangement of the system previous to the establishment of the catamenial discharge; while, in case $\mathbf{3}$, the exciting causes of the malady were complex, the most manifest being the influence of lead. The treatment of this latter case was excessively timid and defective; had the boy been freely purged on his admission into the hospital, it is evident that all the symptoms of the com. plaint wonld have been speedily dissipated. Amongst the causes of tremor enumerated by Frank, are mental emotions, fright, and difficult menstruation; he also regards atony of the system and cerebral congestion, as frequent exciting causes. The latter, however, more commonly refer to adult persons, for atony or debility are more apt to induce chorea in the child.

\section{ENCYSTED TUMOURS SUCCESSFULLY TREATED BY \\ PUNCTURE AND INJECTION.}

\section{To the Editor of THE LANCET.}

SIR:-Not being aware that the above method of removing encysted tumours has been previously practised, and being prevented by the appointment that I now hold from gaining, personally, further experience as to its efficacy (no person having such deformities being admitted into the naval service), $I$ am anxious, through the medium of your Journal, to ascertain whether the same operation has been practised by any one else, and, if so, to be informed of the results of it. In October, 1833, I was first induced to try it in the case of a young woman, residing in one of the southern connties of Scotland, who, from childhood, had been disfigured by a tumour of this

No. 799 . description, situated on the right temple, which, in size and shape, resembled an egg. As usual, its growth had been very gradual, and unattended with pain, being, when first observed, about the size of a pea, situated at the external commissure of the eyelid, whence it had extended, outwards, over the temporal aponeurosis, being anteriorly covered by the concentric fibres of the orbicularis palpebrarum muscle, as was very obvious from the effect produced on the tumour when the patient attempted to close the eye. A few years previously my friend Mr. Manners, surgeon in Berwick-onTweed, had removed from my own person a tumour precisely similar, when, in order to reach the cyst, he found it necessary to divide freely the fibres of this muscle, which, by the gradual increase of the subjacent tumour, were spread out in a layer between the integuments and cyst. For a very long time afterwards I had the greatest difficulty in voluntarily closing the eye of the affected side, and, at the present hour, the opening and closing of both eyes can only be performed syuchronously by a considerable effort. From the similarity that existed between the two tumours I hesitated to perform an operation that was likely to be attended with scarcely less inconvenience than the tumour itself. I resolved, instead, to puncture the sac with a lancet at its posterior portion, where it was not covered by the fibres of this muscle, to express its contents, and then inject some stimulating fluid, with the intention, however, of having recourse to the usual practice in event of its proving unsuccessful, or any unpleasant cousequences ensuing. The puncture being made, the atheromatous contents of the cyst were evacuated by the spasmodic action of the muscle alone, which continued for upwards of a minute; the sac was then injected with coarse "grain whiskey," the stimulant most accessible in a northern cottage. This was retained for about a minute, during which the patient complained of a slight burning sensation. A compress, moistened with vinegar, was then applied over the site of the tumour, and secured there by a bandage, the eye being kept covered up. On removing the dressing three days afterwards, not the slightest vestige of a tumour having existed was perceptible, except the red spot that indicated the site of the puncture. Between that year and Angust, 1836, equally successful results followed the same operation in five other cases; in two the tumours were somewhat larger than a walnut, and situated on the scalp, the patients being a man and woman, both above fifty; in one case, that of a young man about twenty years of age, the tumour extended from near the centre of the forehead down to the very margin of the right eyelid ; in another, a young married woman, it was situated on the left side of the nape of the 21 
neck, and was about the size of an egg; and, in the last, that of an old pedlar, it was of a pyramidal form, occupying the angle between the nose and cheek, and had attained such a size as materially to obstruct the vision of the corresponding eye. In three of the cases the contents consisted of brainlike matter; in two, of a glairyfluid; and in one, they resembled most closely the yolk of a hard boiled egg in appearance, though not in consistence. The fluid injected in one or other of these cases was either common grain whiskey, brandy, or a solution of common table salt in water.

With the exception of the pedlar, I had an opportunity of seeing all the parties operated on in July last, and in no instance had the slightest tendency to a recurrence of the tumour evinced itself; indeed, in all of them, after the first week, the redundant integuments had so contracted that no one could have suspected them to have formed so recently the walls of such bulky protuberances. The extreme simplicity of this operation has much to recommend it; not only is it attended with less pain, but with little or no disfigurement, which last advantage will entitle it to a decided preference over the operation by excision, should farther experience demonstrate its results to be equally satisfactory in the practice of others as in mine. The situation which these tumours generally occupy being the head, neck, and face, the scar left by the common operation has been the means of blighting the prospects of many an otherwise agreeably-featured female, and even of our own ruder sex being blemished with such unseemly scars, a stranger is apt to ascribe a pugnacity of character which we may not deserve. I have the honour to be, Sir, your very obedient servant,

\section{Alex. A. Carr,}

Member of the Royal College of Surgeons, Edinburgh, and Assist.-Surg., R.N.

\section{Sheerness Dockyard,}

Dec. 11, 1838.

P.S. I would not for a moment have it supposed that $I$ consider this mode of treatment applicable to the very large encysted tumours that are occasionally met with, but only to those which we fall in with daily on the head, face, and neck, not much exceeding the size of an egg. I may remark, however, that $I$ am convinced that in the operation by excision the dangerous consequences of allowing any portion of the cyst to remain behind has been greatly over-rated. I have sometimes failed in attempting to extirpate it completely, in which cases one of the above stimulants was applied to the raw surface; in no jnstance did any bad results follow:
SALTS OF MORPHINE. ADMINISTRATION OF MERCURY. CONSTIPATION.

\section{To the Editor of The Lancet.}

SIR :- I am sorry to see in your last week's LANCET a statement, taken from M. Raspail, regarding morphine and its acetate, unguarded by any note or remark of your own. Should any beginner read it, who is about to use morphine for the first time, the chances are that a dangerous dose may be administered. I have used morphine (ace. tate and muriate) often, but in severe neu. ralgic cases, or in suppuration round nerves which, more than mere neuralgy, produces agonising pain. I have not been able to use more than two grains at a dose without producing lengthened and excessive stupidity, and this not more than thrice repeated in twenty.four hours. Venturing further, I have been warned by incipient subsultus tendinum to desist. I have known a grain (I speak of the acetate) produce, in an adult, a long and doubtful coma; doubtful, I nean, during its action, as to the result. I have known half a grain, in partial suppressio urinæ, completely to stop the secre. tion, and, thus, doubly, that is, directly by its narcotic efict, and indirectly by the sup. pression, to produce coma. My experience, extensive, though short in time, teaches me never to begin with more than one-third of a grain of the genuine drug; gradually I go on to the quantity deemed requisite, and thus $I$ have given to an infant, three montlis old, as much as one grain in twenty-four hours, having previously crept on very cautiously, taking care that the secretions are freely going on. I suspect, from M. Ras. pail's recent work on botany, that he is, even in scientific subjects, very much of a visionary; in this it appears that he is mis. chievonsly so.

While I am writing I will advert to two or three other matters.

I think, while there are so many purgatives of more innocent qualities, it can scarcely be right, in obstinate and long-continued costiveness, to administer much uercury. Especially should it not be repeated day after day, the bowels being inactive all the time. In simple costiveness, a pill of mercury, at night, followed by a brisk saline in the morning, just before a warm tea or coffee breakfast, may he very good, but if no action be produced I should give no more mercury. In a fit of constipation, having existed for some length of time, I should scarcely venture to give a dose of mercury, especially if the patient have ever been freely salivated before,-a process that renders resalivation often more easy than desirable. Two ladies whom I attend, warn me of the mercurial whish I may have ad. 